\title{
Self-Reported Abortion-Related Morbidity: A Comparison of Measures in Madhya Pradesh, India
}

By Laura Nyblade, Jeffrey Edmeades and Erin Pearson

Laura Nyblade is director of Stigma, Discrimination and Gender, and Jeffrey Edmeades is a social demographer, both at the International Center for Research on Women, Washington,

DC. Erin Pearson is a doctoral student, Department of Population, Family and Reproductive Health, Johns Hopkins Bloomberg School of Public Health, Baltimore, MD, USA.
CONTEXT: Globally, abortion-related morbidity places a largely unmeasured physical, social and economic burden on women, yet little research has examined population-level morbidity, particularly in developing countries.

METHODS: Data were drawn from a representative 2002 survey in Madhya Pradesh, India, of married women aged 15-39 who had at least one child; the analysis examined 966 abortion attempts associated with 737 pregnancies. The prevalence and severity of self-reported morbidity were determined using a symptom-based measure and a bed rest-based measure. Comparative and concurrency analyses assessed how the measures captured and categorized morbidity, and how their results differed between rural and urban settings and by provider and method used.

RESULTS: Both measures found relatively high levels of abortion-related morbidity: The symptoms measure recorded morbidity in $58 \%$ and $46 \%$ of abortion attempts in rural and urban areas, respectively, and the bed-rest measure did so in $38 \%$ and $29 \%$ of attempts in these areas. With either measure, the proportion of attempts resulting in severe morbidity was higher for rural than for urban women. A substantial proportion of attempts were categorized as resulting in moderate or severe morbidity under the symptoms measure and in no morbidity under the bed-rest measure (16-20\%), and a significant proportion were categorized as leading to severe morbidity under the first measure and to no or moderate morbidity under the second measure (6-17\%). Differences also appeared in how the measures assessed morbidity according to the provider and method used.

CONCLUSIONS: Each measure captured a distinct dimension of abortion-related morbidity, which suggests that multiple measures should be used to more fully assess the burden of morbidity among women in developing countries. International Perspectives on Sexual and Reproductive Health, 2010,36(3):140-148
Globally, unsafe abortion results in a heavy burden of preventable mortality and morbidity. The vast majority of unsafe abortions-98\%-occur in developing countries, and more than half occur in Asia. ${ }^{1}$ An estimated 66,500 women die annually from complications of unsafe abortion, ${ }^{2}$ and a much greater, and largely uncounted, number suffer morbidity. ${ }^{1,3}$ Furthermore, an estimated 7.4 million disability-adjusted life years are lost annually as a result of unsafe abortion, ${ }^{4}$ and each year 1.6 million women suffer secondary infertility and 3-5 million experience chronic reproductive tract infections. ${ }^{5}$ The cost of treating complications of unsafe abortion is a substantial burden on struggling health care systems in the developing world, where the direct cost is estimated at \$375-\$838 million annually; women and families pay an additional $\$ 600$ million out of pocket. ${ }^{5}$ In addition to these economic costs, abortionrelated morbidity takes a largely unmeasured toll on women, not only physically and emotionally, but also in disruption of their daily social and economic activities.

Despite the considerable physical, economic and social costs of abortion-related morbidity in developing countries, there is a dearth of data on population-level morbidity in these settings. 1,3,6 These data are essential both for drawing policymakers' attention to the importance of addressing abortion-related morbidity and for providing an evidence base from which to develop effective strategies to reduce it. The difficulty of measuring morbidity is another challenge, especially given the lack of a standard set of measures. This study documents the population-level abortion-related morbidity in Madhya Pradesh, India, and compares the performance of two measures designed to capture different dimensions: the effect of such morbidity on women's physical health and on their ability to perform daily social and economic activities. We hope to focus attention on how morbidity is measured, and improve the understanding of how abortion-related morbidity is influenced by the provider and method used.

\section{MEASURING MORBIDITY}

The measurement of abortion-related mortality and morbidity poses many challenges in developing countries. Where abortion is illegal, or in countries where it is legal but most abortions still occur outside the formal or legal health care system, official records gathered at health facilities omit a large proportion of abortions and associated morbidity. This situation is particularly common in rural settings, where access to medical services is poorer, and in contexts where abortion is stigmatized. Both of these situations may lead women to seek out "extralegal" providers to avoid disclosure of their actions. ${ }^{6-8}$ Such 
women are not represented in studies relying on facilitybased samples unless they need further services because of complications or a continuing pregnancy. ${ }^{9}$ Furthermore, even in settings where abortion is legal, women seen in health facilities are likely to differ in key characteristics (e.g., family support, income and education) from women who do not use formal health care, which makes it difficult to generalize the morbidity findings of clinic-based studies to the broader population of abortion seekers.

Past research in this area has often focused exclusively on clinical complications, particularly in studies using facility-drawn samples. While this approach is the most accurate for capturing morbidity from a medical perspective, it offers little opportunity for exploring morbidity from women's perspectives. As a result, studies based on this approach are unable to explore questions such as which symptoms or complications matter or are significant enough to women to report as morbidity, what they cost in terms of disruption to women's daily lives and what the characteristics of the abortion-seeking process are, particularly for abortions sought outside of health facilities. These types of information are best collected directly from women themselves, but this approach presents challenges of its own. Whereas measuring morbidity and its severity in formal health care settings is well defined on the basis of clinically observed and clearly understood symptoms, ${ }^{10,11}$ measuring self-reported morbidity in qualitative studies or through surveys is more difficult. Asking women to report morbidity in clinically defined terms is often not feasible, as many women have never received formal medical care for postabortion complications or may not know the clinical terms for the complications they experienced. Women may also rate the severity of morbidity differently from medical providers. Symptoms or complications that are significant or severe enough to be recalled by women may also differ across cultures, between urban and rural settings, and by whether and how pain is managed. ${ }^{9}$ Issues of causality and recall also pose challenges, as women may be reporting on an event that occurred in the distant past.

Given these challenges, it is not surprising that relatively few studies have been conducted on morbidity outside clinical settings. Like self-perceived (or self-reported) morbidity measurements in other fields, ${ }^{12,13}$ abortion morbidity measurements typically focus on measuring prevalence and severity of symptoms or functional disability. Previous studies of self-perceived abortion morbidity have used a range of measures to classify morbidity and its severity, posing an additional challenge of comparability across settings.

Some of these studies asked women about a simplified list of symptoms that reflect the main clinically defined complications of unsafe abortion..$^{9,14-17}$ These generally include a range of questions about bleeding, fever, foulsmelling discharge, pain, incomplete abortion, general weakness, and trauma or physical damage to the body. A few studies, particularly those related to medication abor- tion using mifepristone and misoprostol, asked about the timing or duration of complications. ${ }^{9,14,17}$

Other studies measured functional disability by asking women about disruptions to daily life that resulted from abortion-related complications. ${ }^{7,15,16}$ Typical measures focused on either the ability to perform daily tasks, such as cooking and caring for children, ${ }^{9}$ or the need for bed rest. ${ }^{16}$ This range of questions reflects the variety of measures used more broadly in measuring morbidity for other conditions, including days confined to bed, days of work missed, days of school missed and whether daily activities were restricted. ${ }^{12,13}$

While there are similarities in the types of questions asked across studies, there are no standardized questionsor assessments of the measures themselves-which presents a challenge for scaling up the collection of selfreported abortion-morbidity data. In particular, we are unaware of any attempt to compare the two types of measures considered here-symptoms or complications and disruption to daily life-in the same population to assess whether they are capturing the same dimensions of the "costs" of morbidity. The present study examines whether they provide similar assessments of the levels and severity of morbidity, whether there are differences by rural-urban location and whether collecting just one measure would adequately capture levels of self-reported morbidity.

\section{SETTING}

The study was conducted in Madhya Pradesh-one of India's poorest states-which is characterized by high fertility rates, traditional social norms, limited infrastructure and a history of underdevelopment. Women in Madhya Pradesh have limited autonomy, reflecting the state's conservative social norms. Child marriage is common throughout the state, and as is typical in this region of India, women face significant restrictions on their personal mobility and are frequently excluded from household decisions, including those related to their own health needs and care. ${ }^{18}$

Since the Medical Termination of Pregnancy Act was passed in 1972, abortion has been legal within the first 20 weeks of pregnancy for a wide array of medical, social and economic reasons. However, awareness of the legality of abortion is low in Madhya Pradesh, making this population more similar to those in settings where abortion is illegal. Despite legalization, the provision of legal abortion services in Madhya Pradesh remains poor. In 1997-1998, the state had only 300 registered abortion centers, or approximately five centers per million people. ${ }^{19}$ At the time of data collection for this study, medication abortion (i.e., use of mifepristone and misoprostol) had not been legalized in India, and the most common abortion method used in these centers was dilation and curettage (D\&C), despite the World Health Organization's recommendation of vacuum aspiration, particularly at early gestational ages. ${ }^{20}$ In part, this recommendation is based on the higher rates of complications associated with $\mathrm{D} \& \mathrm{C}^{1,21}$ 
The vast majority of abortions in Madhya Pradesh and elsewhere in India are believed to be performed outside of registered abortion centers and are not reported in government records. ${ }^{* 15,22}$ Illegal abortions in India are estimated to outnumber legal ones by a factor of 3-8.23,24 About $90 \%$ of the estimated six million induced abortions in India each year are performed illegally by uncertified medical or nonmedical practitioners, contributing to high maternal mortality. ${ }^{8}$ In Madhya Pradesh, maternal mortality is higher than in India as a whole; according to data from the 2004-2006 Sample Registration System, its maternal mortality ratio is 335 deaths per 100,000 births, compared to 254 per 100,000 in the country overall. ${ }^{25}$

\section{METHODS}

Data

The data come from a 2002 survey of 2,444 married women who were aged 15-39 and had at least one child. The survey used a narrative interviewing technique that built on a prior qualitative phase, and was pilot-tested prior to implementation. ${ }^{26}$ Respondents were selected using a stratified-cluster sampling approach to ensure that data were representative of the state; urban areas were oversampled to enable the analysis of differences between urban and rural areas. In addition to information on the characteristics of women and their households at the time of the survey, retrospective information was collected on each pregnancy experienced, resulting in a data set of 9,127 pregnancies with a known outcome.

Analyses were based on 737 pregnancies during which an attempt was made to abort the pregnancy; 347 pregnancies were contributed by 284 rural women, and 390 were contributed by 290 urban women. In cases where multiple abortion attempts were made, each attempt was included separately, resulting in a total of 966 individual attempts. ${ }^{\dagger}$ All attempts were included, regardless of whether they led to a completed abortion; an attempt was defined as any action taken by the woman to terminate the pregnancy. ${ }^{\ddagger}$ A variety of data were collected about each attempt, including where she went for the abortion, the advice or treatment received, any resulting complications and the use

\begin{tabular}{|c|c|c|c|c|}
\hline \multirow[t]{2}{*}{ Symptom } & \multicolumn{2}{|c|}{$\begin{array}{l}\text { Rural } \\
(\mathrm{N}=451)\end{array}$} & \multicolumn{2}{|c|}{$\begin{array}{l}\text { Urban } \\
(\mathrm{N}=515)\end{array}$} \\
\hline & $\%$ & No. & $\%$ & No. \\
\hline None & 41.2 & 186 & 54.0 & 279 \\
\hline Pain & 38.4 & 173 & 27.0 & 139 \\
\hline Excessive bleeding & 25.3 & 114 & 9.9 & 51 \\
\hline Incomplete abortion & 3.8 & 17 & 1.9 & 10 \\
\hline Infection/fever & 6.7 & 30 & 3.9 & 20 \\
\hline Weakness & 31.7 & 143 & 24.7 & 127 \\
\hline Damage to uterus/vagina & 0.2 & 1 & 0.6 & 3 \\
\hline Other & 1.8 & 8 & 1.6 & 8 \\
\hline
\end{tabular}

of follow-up care. Information on background characteristics was also collected: parity at the time of the abortion attempt, previous number of attempts to terminate the index pregnancy, woman's and husband's education level (zero, $1-9$, or 10 or more years) and gestational age.

\section{Symptom-Based Measure}

This measure was based on a simplified set of abortionrelated clinical symptoms and complications (Table 1) that women were likely to be aware of and be able to name (excessive bleeding, incomplete abortion, infection or fever, and damage to the uterus or vagina), as well as less clinical symptoms that were clearly important to women (pain and weakness), as reported by participants in other studies on morbidity and in the qualitative and pilot-testing phases of this study. An "other" category included additional symptoms.

Although data were collected on bleeding, no information was gathered on the amount or duration of bleeding; the occurrence of excessive bleeding was based on the woman's perspective. To address the difficulty of classifying excessive bleeding in terms of the severity of morbidity it represented, we examined the effect of reclassifying such reports for all provider and method combinations by using information on the reported number of days of bed rest associated with the abortion attempt. Reports of excessive bleeding that included three or fewer days of bed rest were reclassified into the moderate morbidity category; as expected, this shifted a significant proportion of cases from the severe to the moderate category. However, the proportion of cases so reclassified differed significantly according to the provider and the method used: More than half of the attempts in which a surgical abortion was performed by a government or private medical provider were reclassified, whereas far smaller proportions of attempts using other providers or methods were reclassified (the largest reclassification included 18\% of attempts, and most included fewer than 1\%).

As a result, the symptom-based measure broke abortion attempts into three categories: attempts that led to severe morbidity-an incomplete abortion, infection or fever, damage to the uterus or vagina, or excessive bleeding accompanied by four or more days of bed rest; attempts that led to moderate morbidity-excessive bleeding accompanied by three or fewer days of bed rest, pain, weakness or other complications; and attempts that resulted in no morbidity-that is, no symptoms or bed rest.

*This study was unable to distinguish between unregistered providers who had some medical training and those who did not. Thus, the quality of care received by women who used unregistered providers, and the severity of resulting abortion-related morbidity, may have varied considerably.

tEighty-seven abortion attempts in which women were refused treatment and took no further action to end the pregnancy were excluded, reflecting our primary interest in the morbidity associated with attempts.

$\ddagger$ This included the effective abortion methods offered in both registered and unregistered abortion centers, as well as such traditional methods as taking unspecified pills, consuming spicy foods, massage or physical exertion. 


\section{Bed Rest-Based Measure}

The bed-rest measure was designed to capture the disruption to daily life caused by morbidity resulting from an abortion attempt. While recent studies have found that most women take some rest following an abortion, ${ }^{27}$ this typically consists of sharing household duties with other household members-poor women in particular are unlikely to be able to take a significant break from domestic and other chores following abortions. ${ }^{28,29}$ Given how unusual it is for women in this setting to completely stop daily activities and be bedridden, the length of bed rest related to an abortion attempt may offer an alternative measure of morbidity that is perhaps as accurate as selfreported clinical symptoms. Bed rest, as opposed to other "daily life disruption" measures (e.g., being unable to cook or care for children), was selected for two main reasons: First, it was thought to be more easily quantified by the women being interviewed; and second, this measure was likely to be less affected by respondent recall issues, as full bed rest that interrupts all activity is an unusual occurrence. Women were asked, with respect to a specific abortion attempt, "Were you bedridden or unable to get up for some period of time because of the complications or side effects? How long could you not get up?" Responses were coded as zero, 1-3, 4-7, and eight or more days; from the pilot survey, it was clear that any bed rest beyond seven days indicated severe morbidity. Accordingly, the bed-rest measure was constructed as follows: severe morbidityattempts that led to eight or more days of bed rest; moderate morbidity-attempts that led to 1-7 days of bed rest; and no morbidity-attempts that led to no bed rest.

\section{Analysis}

Our aim was twofold: to document the prevalence and severity of self-reported abortion-related morbidity, and to improve understanding of the measurement of populationlevel morbidity by comparing symptom-based and bed rest-based measures. To assess how these two measures performed in this context and the implications for our understanding of overall abortion-related morbidity in Madhya Pradesh, we adopted a multistage analytical strategy. First, we compared how the measures categorized the prevalence and severity of morbidity experiences, and how they differed between rural and urban settings; Pearson's chi-square tests were used to assess differences. Second, we examined the concurrency between the two types of measures. Finally, we considered how the results yielded by the measures differed according to provider type and abortion method used.

\section{RESULTS}

\section{Background Characteristics}

Among abortion attempts by married women in Madhya Pradesh, the mean number of children at the time of the attempt was 2.9; the mean number of previous attempts at terminating the index pregnancy was 0.4 (Table 2). Nearly half of the attempts were made by women with no schooling, almost four in 10 by women who had $1-9$ years of education and one in six by women who had 10 or more years of education; overall, 19\% of attempts were made by women whose husband had no schooling, $42 \%$ by those whose husband had 1-9 years of education and $39 \%$ by women whose husband had at least 10 years of schooling. In $86 \%$ of the abortion attempts, the gestational age was 1-3 months. Forty-two percent of attempts were made by the woman herself; $38 \%$ and $13 \%$, respectively, were made by private or government providers and $7 \%$ were made by others. Ingesting pills was the most common method used

TABLE 2. Means and percentage distributions of abortion attempts, by selected characteristics, according to rural or urban residence

Characteristic All Rural Urban

MEANS

Parity at time of abortion attempt $2.9 \quad 3.2 \quad 2.6$

Previous no. of attempts to end

$\begin{array}{llll}\text { index pregnancy } & 0.4 & 0.4 & 0.4\end{array}$

PERCENTAGE DISTRIBUTIONS

Woman's education (yrs.)

0

1-9

$\geq 10$

$\begin{array}{lll}45.6 & 56.1 & 22.0^{*} \\ 37.8 & 35.0 & 44.0\end{array}$

Husband's education (yrs.)

0

$1-9$

$\begin{array}{lll}16.7 & 8.9 & 33.9^{* * *}\end{array}$

$\geq 10$

$\begin{array}{lll}18.7 & 22.8 & 9.5^{* *}\end{array}$

$42.1 \quad 45.1 \quad 35.6$

$\begin{array}{lll}39.2 & 32.2 \quad 55.0^{*}\end{array}$

Gestational age (mos.)

$1-3$

$4-5$

$\begin{array}{lll}85.7 & 85.2 & 86.9\end{array}$

Provider

Self

$\begin{array}{lll}14.3 & 14.8 \quad 13.1\end{array}$

Private

Government

Other

$42.1 \quad 48.6$

$37.5 \quad 32.2$

$13.2 \quad 10.1$

$\begin{array}{ll}7.3 & 9.2\end{array}$

$27.5^{* *}$

$49.3^{* *}$

$20.0^{*}$

Abortion method

Pillsł

Surgical

$36.9 \quad 39.7$

$29.0 \quad 21.6$

$34.1 \quad 38.7$

$30.7^{*}$

Other§

$38.7 \quad 23.6$

Attempt led to symptom-based complication

$\begin{array}{lrrr}\text { Yes } & 52.9 & 56.6 & 44.7 \\ \text { No } & 47.1 & 43.4 & 55.3\end{array}$

Follow-up care received after experiencing complicationt†

$\begin{array}{lrrr}\text { Yes } & 36.5 & 38.3 & 31.4\end{array}$

$\begin{array}{llll}\text { No } & 63.5 & 61.7 & 68.6\end{array}$

Attempt ended in completed abortion

$\begin{array}{llll}\text { Yes } & 50.2 & 46.7 & 58.1\end{array}$

$\begin{array}{llll}\text { No } & 49.8 & 53.3 & 41.9\end{array}$

$\begin{array}{llll}\text { Total } & 100.0 & 100.0 & 100.0\end{array}$

${ }^{*} \mathrm{p}<.05 .{ }^{* *} \mathrm{p}<.01 .{ }^{* * *} \mathrm{p}<.001 .+\mathrm{p}<.10$. IIncludes malaria pills and other unspecified pills used in an abortion attempt; medication abortion was neither legal nor available in Madhya Pradesh during the survey period. SIncludes insertion of an object into the vagina; eating or drinking spicy foods, hot drinks or herbs; massage; carrying heavy loads; and intentional jumping or falling. ††Among cases involving complications. Notes: Some women made multiple attempts, and Ns include all such attempts; however, 45 cases were excluded because of incomplete information. Proportions are weighted to account for oversampling of urban areas. 


\begin{tabular}{|c|c|c|}
\hline Measure & $\begin{array}{l}\text { Rural } \\
(\mathrm{N}=444)\end{array}$ & $\begin{array}{l}\text { Urban } \\
(\mathrm{N}=514)\end{array}$ \\
\hline \multicolumn{3}{|c|}{ Symptoms } \\
\hline None & 41.9 & $54.3 \dagger$ \\
\hline Moderate & 28.9 & 33.7 \\
\hline Severe & 29.2 & $12.1^{* *}$ \\
\hline \multicolumn{3}{|l|}{ Bed rest } \\
\hline None & 61.9 & $70.6+$ \\
\hline Moderate & 21.4 & $16.2^{* *}$ \\
\hline Severe & 16.7 & 13.2 \\
\hline Total & 100.0 & 100.0 \\
\hline
\end{tabular}

(37\%), * followed by "other" (e.g., insertion of an object into the vagina, eating or drinking spicy foods, hot drinks or herbs, carrying heavy loads, or jumping or falling; 34\%) and surgical methods (29\%). For 37\% of attempts that involved symptom-based morbidity, women reported receiving follow-up care (as did half of those who had severe complications; not shown). Half of all attempts resulted in completed abortions.

In the sample of all abortion attempts, rural women had more children at the time of the attempt, on average, than did urban women (3.2 vs. 2.6), and rural women and their husbands had less schooling than their urban counterparts (e.g., the proportions in rural and urban areas with no schooling were $56 \%$ and $22 \%$, respectively, among women, and $23 \%$ and $10 \%$ among husbands). Among attempts reported by rural women, $49 \%$ were made by the woman herself, as were $28 \%$ of attempts reported by urban women, whereas attempts by rural women were less likely than those by urban women to be with a private provider (32\% vs. $49 \%$ ) or a government provider (10\% vs. 20\%). For both groups, however, abortion attempts were more likely to have been with a private provider than a government one (32\% vs. 10\% among rural women, and $49 \%$ vs. $20 \%$ among urban women). Finally, attempts were least likely to happen with other types of providers (9\% and 3\%, respectively, among rural and urban women), typically traditional abortion providers.

Women in rural and urban settings also differed in the abortion methods they used, partly reflecting differences in where they sought abortion services. Abortion attempts made by rural women were less likely than those made by urban women to rely on surgical methods ( $22 \%$ vs. $46 \%$ ) and more likely to rely on pills (40\% vs. $31 \%$ ) or other methods (39\% vs. 24\%). As might be expected given these differences, attempts by rural women were less likely to result in a completed abortion than attempts by urban women (47\% vs. 58\%), although this difference was not statistically significant. When only attempts made at government or private providers were considered, $58 \%$ of attempts by rural women and $74 \%$ of those by urban women resulted in a completed abortion (not shown).

\section{Prevalence and Severity of Morbidity}

Fifty-three percent of all abortion attempts led to some symptom-based morbidity (see Table 2). Overall, the measure of morbidity based on symptoms found higher levels of abortion-related morbidity than did the measure based on time spent in bed rest (Table 3). Furthermore, 58\% of abortion attempts in rural areas resulted in at least some symptom-defined morbidity, whereas $46 \%$ of attempts in urban areas led to such morbidity. Similarly, attempts by rural women were more likely than those by urban women to have led to bed rest (38\% vs. 29\%).

With use of either measure, the proportion of abortion attempts resulting in severe morbidity was higher for rural than for urban women. With the symptom-based measure, $29 \%$ of rural and $12 \%$ of urban attempts resulted in morbidity that was classified as severe, and this difference was significant. With the bed rest-based measure, 17\% of attempts in rural areas and 13\% in urban areas resulted in severe morbidity, however, this difference was not significant. In addition, the proportion of abortion attempts that resulted in severe morbidity varied by measure and urbanrural setting. Among urban women, the proportions of attempts with severe morbidity were similar for the two measures ( $12 \%$ and $13 \%$ ), whereas the proportions differed substantially among rural women (29\% vs. $17 \%$ ).

Another way to compare the two measures is to assess their agreement in a cross-tabulation. Forty-two percent of abortion attempts made by rural women were categorized as "no morbidity" under both measures, compared with $54 \%$ of attempts by urban women (Table 4). Yet a substantial minority of attempts were categorized by the symptom-based measure as resulting in moderate or severe morbidity and by the bed rest-based measure as "no morbidity" ( $20 \%$ by rural women and $16 \%$ by urban women). Furthermore, 17\% of attempts by rural women and $6 \%$ of attempts by urban women were categorized as causing severe morbidity under the symptom-based measure and as either no or moderate morbidity under the bed-rest measure. Only $12 \%$ and $6 \%$ of abortion attempts made by women in rural and urban areas, respectively, were classified as severe under both measures. The differences in abortion-related morbidity between rural and urban women may be a function of the process through which they attempt to obtain an abortion, in terms of both the types of providers they seek and the methods they use.

\section{Patterns of Abortion-Seeking Behavior}

According to both measures, abortion attempts made by women themselves were generally less likely to result in morbidity than those made with the assistance of someone else, whether a government or private medical provider or a nonmedical provider, reflecting in part the broad definition of abortion attempt used in this study (Table 5). For example, using the symptom measure, 54\%

* Medication abortion was neither legal nor available in Madhya Pradesh during the survey period; however, information was available on the use of malaria pills and other pills for inducing an abortion. 
of attempts made by women themselves resulted in no morbidity, compared with $34-44 \%$ of attempts under five of the six other method and provider categories. Similarly, using the bed-rest measure, $76 \%$ of attempts by women themselves led to no morbidity, compared with 44-69\% of attempts under five of the other categories. There were two exceptions: under the symptom method, attempts made at government facilities with nonsurgical methods (54\% resulted in no morbidity), and under the bed-rest measure, attempts at private medical facilities that involved pills ( $75 \%$ resulted in no morbidity).

Under the bed-rest measure, moderate or severe morbidity was more likely to occur with surgical abortion attempts than with any other type of attempt (54-56\% vs. 24-42\%). In contrast, under the symptom-based measure, reports of moderate or severe morbidity were highest in nongovernmental settings (61-66\%) and lowest in governmental clinics (46-56\%). Although most of the morbidity associated with nonsurgical methods performed by private providers was classified as moderate under the symptom measure ( $42 \%$ for pills and $47 \%$ for other), a large proportion was classified as severe (19-20\%). The reverse occurred for attempts made with nonmedical providers: Forty-five percent of morbidity was classified as severe and $17 \%$ as moderate.

The relatively high levels of morbidity reported for surgical procedures, particularly in terms of bed rest, may be offset by the higher rates of completed abortions that result from their use relative to other methods. Ninety-four percent and $79 \%$ of surgical attempts made by urban and rural women, respectively, resulted in completed abortions, compared with $21 \%$ and $32 \%$ of nonsurgical attempts by these groups (not shown). Indeed, the average number of attempts for women using a surgical method was 1.0, whereas the average number for women using other methods was 1.4 ( $\mathrm{p}=0.000$ ), thus reducing the first group's potential overall morbidity burden. It is important to note that women who went to a medical provider often received ineffective treatment, especially from private
TABLE 4. Concurrency between symptom and bed-rest measures of abortion-related morbidity, by rural or urban residence

\begin{tabular}{llll|lcl} 
Symptoms & \multicolumn{2}{l}{} \\
\cline { 2 - 7 } & \multicolumn{2}{l}{ Rays of bed rest } \\
\cline { 2 - 7 } & None & Moderate & Severe & None & Moderate & Severe \\
\hline None & 42.1 & 0.0 & 0.0 & 54.3 & 0.0 & 0.0 \\
Moderate & 14.9 & 9.2 & 4.7 & 15.6 & 10.9 & 7.2 \\
Severe & 5.0 & 12.2 & 11.9 & 0.8 & 5.3 & 6.0
\end{tabular}

providers: Forty-three percent who used a private provider received nonsurgical treatment, as did 30\% who used a government provider. That such large proportions of women who visited medical providers received less effective care indicates a substantial unmet need for effective abortion services. Furthermore, these figures mask the fact that some women required multiple attempts to complete the abortion.

Sixty-five percent of initial abortion attempts among urban women and $51 \%$ of such attempts among rural women ended in a completed abortion. When first attempts failed, only $54 \%$ of those by urban women and $44 \%$ of those by rural women were followed by another attempt. Forty-two percent of second attempts by urban women and $35 \%$ by rural women resulted in a completed abortion. Of second attempts that failed, $65 \%$ of those by urban women and $50 \%$ of those by rural women were followed by a third attempt; $15 \%$ of these attempts by urban women and $30 \%$ by rural women ended in a completed abortion. There were very few cases in which women made more than three abortion attempts.

\section{DISCUSSION}

Abortion-related morbidity, particularly in developing countries, results in a heavy burden on women, their families and the health care system, 1,3,4 yet population-level data on such morbidity are scarce, as are comparative data on the morbidity experiences of urban and rural women. The present study produced several notable findings on

\begin{tabular}{|c|c|c|c|c|c|c|c|}
\hline \multirow[t]{2}{*}{ Measure } & \multirow{2}{*}{$\begin{array}{l}\text { Self } \\
(N=350)\end{array}$} & \multicolumn{2}{|c|}{ Government medical provider } & \multicolumn{3}{|c|}{ Private medical provider } & \multirow{2}{*}{$\begin{array}{l}\text { Nonmedical provider§ } \\
(\mathrm{N}=60)\end{array}$} \\
\hline & & $\begin{array}{l}\text { Surgical } \\
(N=103)\end{array}$ & $\begin{array}{l}\text { Nonsurgical } \\
(\mathrm{N}=44)\end{array}$ & $\begin{array}{l}\text { Surgical } \\
(N=226)\end{array}$ & $\begin{array}{l}\text { Pillst } \\
(\mathrm{N}=113)\end{array}$ & $\begin{array}{l}\text { Other‡ } \\
(\mathrm{N}=57)\end{array}$ & \\
\hline \multicolumn{8}{|c|}{ Symptoms } \\
\hline None & 53.8 & 44.4 & 54.4 & 39.3 & 37.9 & 34.3 & 38.5 \\
\hline Moderate & 22.5 & 34.5 & 12.7 & 41.9 & 42.3 & 46.8 & 16.8 \\
\hline Severe & 23.7 & 21.2 & 32.9 & 18.8 & 19.8 & 18.9 & 44.7 \\
\hline \multicolumn{8}{|c|}{ Bed rest (days) } \\
\hline 0 & 75.9 & 46.5 & 69.2 & 44.2 & 75.2 & 67.6 & 57.8 \\
\hline $1-3$ & 14.0 & 20.3 & 17.0 & 28.6 & 21.0 & 30.2 & 19.7 \\
\hline$\geq 4$ & 10.1 & 33.2 & 13.8 & 27.2 & 3.7 & 2.2 & 22.5 \\
\hline Total & 100.0 & 100.0 & 100.0 & 100.0 & 100.0 & 100.0 & 100.0 \\
\hline
\end{tabular}


abortion-related morbidity and on the measures based on symptoms and bed rest.

First, our results confirmed that measuring self-reported morbidity on a large scale is feasible and suggests significant levels of abortion-related morbidity. Although the levels of morbidity we found were high, they are within the range reported in other research in India ${ }^{15,16}$ and other settings. 5,30,31 This is important because accurate measurement in larger-scale quantitative surveys will allow for the collection of data that are more representative of the general population, and these data will provide policymakers with information on the prevalence of abortion-related morbidity within large population groups, on its effects on women's lives and on the determinants of such morbidity.

Second, the comparison of the two measures confirmed that although they assessed the same underlying morbidity, they captured different aspects of the morbidity experience. Use of the measures provided different overall levels of morbidity, with the symptom-based measure suggesting higher levels of morbidity than the bed-rest measure. This was true for all combinations of provider and method employed (though differences for surgical abortions were small), which implies that sole reliance on a "disruption to daily life" measure would miss a substantial proportion of overall morbidity when nonsurgical methods are used. Conversely, reliance on a symptombased measure may overstate the actual effect of this morbidity on women's lives. In addition, use of the two measures revealed not only an overall difference in the classification of the severity of morbidity, but a difference in its classification in rural versus urban settings, as well as by provider and abortion method. Indeed, the difference between the proportions of attempts classified as resulting in severe morbidity by the two measures was considerably larger in rural areas than in urban areas. However, for moderate levels of morbidity, the difference between the two measures was larger in the urban than in the rural areas.

When assessed using the bed-rest measure, surgical abortions resulted in higher morbidity, likely because of a number of factors, including greater support from household members for women who used this procedure and the higher expected morbidity associated with the D\&C procedure (e.g., blood loss and other complications), which was the most common surgical method in India at the time of this study. Furthermore, though we knew of no standardized guidelines for clinicians' recommending bed rest following a $\mathrm{D} \& \mathrm{C}$, it is possible that women were instructed to take bed rest following this procedure. In addition, such a request may be more respected by family members than if the recommendation is made by a noncertified abortion provider (assuming that the family is aware of the attempt).

Our concurrency analysis revealed that the two measures were capturing different aspects of morbidity, and that there are a number of possible explanations for these differences. It is likely that in Madhya Pradesh, women in both rural and urban areas found it difficult to take sustained periods of time away from their employment or domestic roles, even when suffering from significant postabortion complications. As a result, the measure based on bed rest may have understated the degree of morbidity experienced by women, especially in rural areas, where the agricultural economy and more conservative social norms may make taking bed rest even more difficult. However, when viewed from this perspective, time spent in bed rest, especially for rural women, may indicate particularly severe morbidity.

These measurement differences highlight the importance of assessing not only the clinical or physical aspects of morbidity, but also how these physical symptoms affect a woman's ability to conduct her daily activities. In addition, because we had data on days of bed rest, we were able to better define one of the symptoms (excessive bleeding) in terms of severity. Having both measures was also important for capturing the differing morbidity experiences of rural and urban women, which is a reflection of the differences in the process of seeking an abortion (e.g., number of attempts in a single pregnancy), the ability to secure a completed abortion, and the availability and quality of service provision. Overall, these results highlight the complexity of the relationship between abortion and morbidity and suggest that a fuller understanding may be possible when data on both dimensions of morbidity are available.

While many of our results were not unexpected for a setting with high levels of poverty, poor infrastructure, low status of women and relatively high use of D\&C, they nonetheless confirmed these expectations and provided evidence supporting advocacy for improved services. A substantial proportion of the abortion attempts in this sample did not result in a completed abortion, and this low completion rate is reflective of the high proportion of womenparticularly those living in rural areas-who attempted abortion themselves or with the assistance of nonmedically trained providers. Furthermore, these attempts resulted in a significant amount of untreated morbidity, and in nearly two-thirds of attempts resulting in morbidity, the women received no follow-up care, including half of those who experienced severe complications. Together, these findings demonstrate the failure of the health care system in Madhya Pradesh to provide women with safe abortion services and postabortion care. While the increased availability of misoprostol and the decreased use of D\&C suggest that women's morbidity will decline if they obtain care from public or private medical centers, most women continue to seek abortions outside of the formal medical system, and therefore remain vulnerable to unnecessary morbidity.

\section{Conclusions}

This study highlights both the burden of abortion-related morbidity in Madhya Pradesh and the value in measuring this morbidity in multiple ways. While the need for improved services is great everywhere, it is clearly greater in 
rural areas. Our findings also demonstrate the need to improve the measurement of self-reported abortion-related morbidity to support the collection of data in a more representative sample of women than those who visit health facilities.

Further exploration of how to measure self-reported morbidity is required so that we can better understand the reliability of measures across cultural contexts (particularly in terms of norms relating to bed rest), the effect of decisions regarding the categorization of relative morbidity levels, the comparability of measures to standardized clinical measures of morbidity, the reliability of retrospective data on bed rest and non-life-threatening complications, and how such data may be shaped by specific features of the medical system, such as standardized recommendations for bed rest following surgical procedures. Until research finds answers to these questions, selfreported data will need to be interpreted with some care. Furthermore, the use of more refined measures of the effects of abortion-related morbidity on women's activity levels, such as the ability to perform specific tasks, should be investigated. Finally, researchers should explore the utility of creating a morbidity measure that combines clinically observable symptoms and complications with information on the practical effect they have on women's daily lives. Such information is critical in the development of standardized measures of self-reported morbidity that capture the full range of women's abortion experiences, including those overlooked by focusing solely on facilitybased measures of morbidity.

\section{REFERENCES}

1. Grimes D et al., Unsafe abortion: the preventable pandemic, Lancet, 2006, 368(9550):1908-1919.

2. Ahman E and Shah I, Unsafe Abortion: Global and Regional Estimates of Incidence of Unsafe Abortion and Associated Mortality in 2003, fifth ed., Geneva: World Health Organization (WHO), 2007.

3. Singh S, Hospital admissions resulting from unsafe abortion: estimates from 13 developing countries, Lancet, 2006, 368(9550):18871892.

4. WHO Global Health Observatory, Mortality and burden of disease: global burden of disease, regional-disability-adjusted life years (DALYS), 2009, <http://apps.who.int/ghodata/\#>, accessed Aug. 2, 2010.

5. Vlassoff $\mathrm{M}$ et al., Economic Impact of Unsafe Abortion-Related Morbidity and Mortality: Evidence and Estimation Challenges, IDS Research Report, Brighton, UK: Institute of Development Studies, University of Sussex, 2008, No. 59.

6. Ganatra B and Johnston HB, Reducing abortion-related mortality in South Asia: a review of constraints and a road map for change, Journal of the American Medical Women's Association, 2002, 57(3):159-164.

7. Ganatra B and Hirve S, Induced abortion among adolescent women in rural Maharashtra, India, Reproductive Health Matters, 2002, 10(19):76-85

8. Johnston HB, Abortion Practice in India: A Review of Literature, Mumbai: Centre for Enquiry into Health and Allied Themes (CEHAT)/Healthwatch, 2002.

9. Elul B et al., Side effects of mifepristone-misoprostol abortion versus surgical abortion: data from a trial in China, Cuba, and India, Contraception, 1999, 59(2):107-114.

10. Jewkes R et al., The impact of age on the epidemiology of incom- plete abortions in South Africa after legislative change, BJOG, 2005, 112:(3)355-359.

11. Rossier $C$ et al., Estimating clandestine abortion with the confidants method-results from Ouagadougou, Burkina Faso, Social Science E Medicine, 2006, 62(1):254-266.

12. Murray CJL and Chen LC, Understanding morbidity change, Population and Development Review, 1992, 18(3):481-503.

13. Ross DA and Vaughan JP, Health interview surveys in developing countries: a methodological review, Studies in Family Planning, 1986, 17(2):78-94.

14. Coyaji K et al., Mifepristone-misoprostol abortion: a trial in rural and urban Maharashtra, India, Contraception, 2002, 66(1):33-40.

15. Johnston HB et al., Where do rural women obtain postabortion care? The case of Uttar Pradesh, India, International Family Planning Perspectives, 2003, 29(4):182-187.

16. Ramachandar L and Pelto PJ, Abortion providers and safety of abortion: a community-based study in a rural district of Tamil Nadu, India, Reproductive Health Matters, 2004, 12(24 Suppl.):138-146.

17. Mitsunaga T, Larsen U and Okonofua F, Risk factors for complications of induced abortions in Nigeria, Journal of Women's Health, 2005, 14(6):515-528.

18. International Institute for Population Sciences (IIPS) and Macro International, National Family Health Survey (NFHS-3), 2005-06: India, Volume 1, Mumbai: IIPS, 2007.

19. Department of Family Welfare, Government of India, Yearbook 1997-98, New Delhi: Family Welfare Programme in India, 1998.

20. WHO, Medical Methods for the Termination of Pregnancy: Report of a WHO Scientific Group, WHO Technical Report Series, Geneva: WHO, 1997, No. 871

21. WHO, Safe Abortion: Technical and Policy Guidance for Health Systems, Geneva: WHO, 2003.

22. Varkey P et al., The reality of unsafe abortion in a rural community in South India, Reproductive Health Matters, 2000, 8(16):83-91.

23. Karkal M, Abortion laws and the abortion situation in India, Issues in Reproductive and Genetic Engineering, 1991, 4(3):223-230.

24. Chhabra R and Nuna S, Abortion in India: An Overview, New Delhi Veerendra Press, 1994.

25. Office of the Registrar General of India, Special bulletin on maternal mortality in India 2004-2006, 2009, <http://www.mp.gov.in/ health MMR-Bulletin-April-2009.pdf>, accessed July 21, 2010.

26. Edmeades J et al., Methodological innovation in studying abortion in developing countries: a "narrative" quantitative survey in Madhya Pradesh, India, Journal of Mixed Methods Research, 2010, 4(3):176-198.

27. Saha S et al., Abortion in Maharashtra: Incidence, Care and Cost, Mumbai: CEHAT, 2004.

28. Ganatra B et al., Understanding women's experiences with medical abortion: in-depth interviews with women in two Indian clinics, Global Public Health, 2010, 5(4):335-347.

29. Visaria L et al., Abortion in India: emerging issues from qualitative studies, Economic and Political Weekly, 2004, 39(46-47):5044-5052.

30. Gebreselassie $\mathrm{H}$ et al., The magnitude of abortion complications in Kenya, BJOG, 2005, 112(9):1229.

31. Kay BJ et al., An analysis of the cost of incomplete abortion to the public health sector in South Africa-1994, South African Medical Journal, 1997, 87(4):442-447.

\section{RESUMEN}

Contexto: A nivel global, la morbilidad relacionada con el aborto impone una carga física, social y económica en las mujeres que, en gran parte, queda sin ser medida; muy pocas investigaciones han examinado la morbilidad a nivel de la población, especialmente en los países en desarrollo. 
Métodos: Los datos se obtuvieron de una encuesta representativa aplicada en 2002 en Madhya Pradesh, India, a mujeres casadas en edades de 15-39 años, que tenían al menos un hijo. El análisis examinó 966 intentos de aborto asociados con 737 embarazos. La prevalencia y la severidad de la morbilidad autoreportada se determinaron usando una medición basada en sintomas y otra basada en la estadía en cama. Mediante análisis comparativos y de concurrencia, se evaluó la forma en que las mediciones captaron y clasificaron la morbilidad y cómo sus resultados difirieron entre entornos rurales y urbanos, asi como por prestador de servicios y método de aborto usado.

Resultados: Ambas mediciones encontraron niveles relativamente altos de morbilidad relacionada con el aborto. La medición de síntomas registró morbilidad en 58\% y 46\% de los intentos de aborto en áreas rurales y urbanas, respectivamente; y la basada en la estadía en cama registró lo mismo en 38\% y 29\% de los intentos en esas áreas. Con cada medición, la proporción de intentos que resultaron en morbilidad severa fue más alta para las mujeres rurales que para las urbanas. Una importante proporción de intentos fueron clasificados como resultantes en morbilidad moderada o severa bajo la medición de síntomas y en morbilidad nula bajo la medición basada en la estadía en cama (16-20\%); y una proporción significativa fue clasificada como conducente a morbilidad severa bajo por sintomas y a morbilidad nula o moderada bajo por estadía en cama (6-17\%). También aparecieron diferencias en la forma en que las mediciones evaluaron la morbilidad según el prestador de servicios y método de aborto usado.

Conclusiones: Cada medición captó una dimensión distinta de la morbilidad relacionada con el aborto, lo que sugiere que debe usarse múltiples mediciones para evaluar más completamente la carga de morbilidad por aborto en las mujeres en los países en desarrollo.

\section{RÉSUMÉ}

Contexte: À l'échelle mondiale, la morbidité liée à l'avortement fait peser un fardeau physique, social et économique rarement mesuré. Or la recherche n'a guère examiné la morbidité au niveau de la population, en particulier dans les pays en développement.

Méthodes: Les données sont extraites d'une enquête représentative menée en 2002 dans l'État du Madhya Pradesh, en
Inde, auprès de femmes mariées de 15 à 39 ans mères d'au moins un enfant. L'analyse examine 966 tentatives d'avortement associées à 737 grossesses. La prévalence et la gravité de la morbidité autodéclarée sont déterminées selon une mesure basée sur les symptômes et une mesure d'alitement. Les analyses comparatives et concurrentielles évaluent la manière dont les mesures capturent et catégorisent la morbidité, ainsi que la différence de leurs résultats entre les milieux ruraux et urbains et selon le prestataire et la méthode utilisée.

Résultats: Les deux mesures révèlent des niveaux relativement élevés de morbidité liée à l'avortement. La mesure des symptômes fait état de morbidité dans 58\% et 46\% des tentatives d'avortement dans les milieux ruraux et urbains, respectivement, et la mesure de l'alitement en fait état dans 38\% et 29\%, respectivement. Pour les deux mesures, la proportion de tentatives aboutissant sur une morbidité grave est supérieure parmi les femmes des milieux ruraux. Une proportion substantielle de tentatives sont catégorisées comme aboutissant sur une morbidité modérée ou grave dans la mesure des symptômes et sans morbidité sous la mesure d'alitement (16\% à 20\%). De même, une proportion important est classée comme menant à une morbidité grave sous la première mesure et à une morbidité nulle ou modérée sous la seconde (6\% à 17\%). Plusieurs différences se révèlent aussi dans la manière dont les mesures évaluent la morbidité en fonction du prestataire et de la méthode utilisée.

Conclusions: Chaque mesure capture une dimension distincte de la morbidité liée à l'avortement, laissant entendre la nécessité de mesures multiples si l'on veut évaluer plus précisément la charge de la morbidité parmi les femmes des pays en développement.

\section{Acknowledgments}

The authors acknowledge the support of The David and Lucile Packard Foundation for data collection and The William and Flora Hewlett Foundation for ongoing research. We are grateful to all of those involved in the data collection, to participants at the 2007 IUSSP seminar Measurement of Abortion Incidence, AbortionRelated Morbidity and Mortality in Paris, to Janna McDougall and Susan Lee-Rife, and to two anonymous reviewers for their comments on an earlier version of this article.

Author contact:Inyblade@icrw.org 